\title{
SOBRE ARQUITECTURA NEOCLÁSICA EN EL CENTRO DE MÉXICO*
}

\author{
JOSÉ GUADALUPE VICTORIA
}

\section{Introducción}

El amplio y variado campo de la historia del arte, desde que éste hizo su aparición como disciplina humanística independiente; o al menos a partir de cuando pretendió constituirse como tal, permitió a sus promotores el echar mano de distintos puntos de vista para el estudio del sujeto primordial de dicha disciplina, o sea la obra de arte, fuera ésta un edificio, un cuadro, una escultura, o cualquier objeto de las artes aplicadas.

Ahora bien, uno de los puntos de vista más socorridos entre quienes se han dedicado a la historia del arte, es el que se refiere justamente a enfocar el estudio de las obras artísticas bajo la perspectiva de la regionalización. Esto se palpa en cierto ámbito como el hispanoamericano. $Y$ aunque no puede negarse la validez didáctica de dicho enfoque, no cabe duda que a veces los resultados no son enteramente satisfactorios.

En el caso del arte mexicano, especialmente el de la época barroca, la regionalización se ha presentado como una vía de más fácil acceso a cierta producción artística cuya nota predominante, en primera instancia, es su diversidad. Ciñéndose a revisar, aunque sea de modo sucinto, la historiografia de la arquitectura barroca novohispana, saltan a la vista un sinnúmero de estudios que ponen énfasis en las distintas variantes regionales. Sea por el ámbito geográfico, los límites cronológicos, los materiales utilizados o el repertorio ornamental, e incluso la iconograíía plasmada en algunas partes del edificio - portadas, cúpulas y rorres-, el resultado final

\footnotetext{
* Este artículo tiene como antecclente la ponencia que, con el mismo título, presenté en el Coloquio sobre ¿ Regionalización en el arte? Teoría y Praxis, cclebrado en la ciüdad de Culiacán, Sinaloa, del 23 al 27 de enero de 1989. Se toman en cuenta los comentarios hechos a la ponencia por la maestra Elizabeth Fuentes Rojas, de la Academia de San Carlos, y de varios participantes en el evento.
} 
en muchos de esos estudios es la utilización de una complicada terminología que frecuentemente, en lugar de clarificar, confunde; sobre todo a aquellos que se acercan por vez primera a esa expresión artística.

En muchos de esos estudios predomina el análisis formal e iconográfico y sólo lateralmente se abordan otros aspectos inherentes a las obras, como puede ser el contexto socioeconómico en el cual surgieron.

Hacemos las consideraciones anteriores porque en este trabajo hemos de referirnos a un solo aspecto de la gran problemática que plantea el estudio de la arquitectura novolispana, o sea el que se refiere al momento final del periodo barroco y al inicio del neoclásico. Advertimos, de antemano, que no se pretende llegar a ninguna conclusión definitiva, dado que no contamos aún con un catálogo exhaustivo de los edificios de ese periodo que existen en todo el país; por lo cual sólo nos referiremos a cinco ejemplos localizados en el centro de México.

Cabe recordar, también, que entre 1750 y 1780 el ritmo constructivo fue muy intenso en todo el virreinato y es precisamente en ese periodo cuando se erigen algunos edificios - religiosos y civiles- más significativos del barroco novohispano; de los cuales pueden mencionarse El Sagrario de México, el Colegio Jesuita de Tepotzotlán, la iglesia de Santa Prisca de Taxco. Todas estas obras fueron construidas siguiendo una tradición centenaria, tanto en su concepción - por parte de los patrones y de los artistas-como en su realización. Es decir, que en ese tiempo se seguía un sistema de trabajo en el que los artistas contaron con cierto margen de libertad para crear obras que a nuestros ojos aparecen como personales. Por eso pareciera que resulta más fácil abordar el estudio de la arquitectura barroca novohispana desde el punto de vista de la regionalización.

Ahora bien, ¿qué ocurre con la arquitectura llamada neoclásica, especialmente la de los inicios? Como todos sabemos la enseñanza académica se implantó en la Nueva España en la década de los ochenta del siglo XVIII. No es el caso referir todos sus propósitos, basta recordar que los artistas -en este caso los arquitectos- hubieron de someterse al nuevo tipo de enseñanza y adoptar un lenguaje artístico casi diametralmente distinto al que muchos de ellos habian manejado por décadas. Uno de los casos más significativos es el de José Damián Ortiz de Castro, a quien volveremos a mencionar en otra parte de este trabajo.

No obstante, el probicma muchas veces no se redujo a la adopción de un repertorio artístico nuevo, sino que iba más allá; por ejemplo cuando fue necesario terminar obras iniciadas en plena época barroca, que por falta de recursos no. Labían podido concluirse. Lo cual implicaba una problemática mayor y en la que intervenían otros personajes como eran 
las autoridades civiles y eclesiásticas, además de los diferentes sectores de la población, particularmente las comunidades indígenas. Los patronos y los artistas, pues, se encontraron ante la disyuntiva de cómo concluir sus edificios: ¿en barroco o en neoclásico?

Los ejemplos estudiados aquí son los siguientes: en primer lugar la catedral de México, por todos conocido; enseguida la iglesia mayor de Tulancingo - más tarde elevada al rango de catedral-y la parroquia de Zimapán, ambas en el estado de Hidalgo. Por último el santuario agustino de Chalma y la parroquia de San Martín Ocoyoacac, sitos en la jurisdicción del Estado de México. Todos estos edificios en la época estudiada caían bajo la jurisdicción del arzobispado de México.

\section{La catedral de México}

En realidad se trata únicamente de la conclusión de su fachada principal, obra del malogrado José Damián Ortiz de Castro (1750-1793), quien proyectó las torres y arregló el remate. Proyecto tan bien logrado, dice Toussaint, "que inmortalizaría a cualquier arquitecto". Ahí, Ortiz de Castro "superando los recursos que podía ofrecer ál arquitecto una construcción enorme, comenzada trabajosamente en el siglo XVI, concluida en su estructura interior y en sus portadas en el XVII y ornamentada con la profusión y la locura del XVIII, Ortiz de Castro logra el único acierto posible. Sin realizar obra arqueológica sino de su tiempo, concibe un original remate para sus torres y esboza una discreta fachada que coronan estatuas.... El secreto del éxito de Ortiz estriba en la armonía y en las excelentes proporciones de su proyecto. Las torres parecen un tanto pesadas pero, dada la superficie de sus bases y la amplitud del templo, no es de creerse que las del proyecto original de Agïero, que desconocemos, fuesen más ligeras, construye su segundo cuerpo calado y el remate originalísimo, en forma de campana, que parece de piedra maciza, no es sino de tezontle, finamente tallado, revestido con chapa de cantera y fuertemente trabado con cinchos de hierro."

Desgraciadamente el arquitecto murió y la obra hubo de ser concluida, todos sabemos, por don Miguel Tolsá; quien hubo de terminar definitivamente la catedral en neoclásico. Triunfaba la modernidad.

\footnotetext{
${ }^{1}$ Manuel Toussaint, Arte Colonial en México, 2a ed., México, UNAM, Instituto de Investigaciones Estéticas, 1962, pp. 219, 220-221
} 


\section{Parroquia de Tulancingo}

Otra de las más significativas intervenciones del arquitecto Ortiz de Castro fue la construcción de la parroquia mayor de Tulancingo, hoy catedral. En realidad, tal como procuramos demostrar en otro trabajo, en este caso tampoco llevó a cabo una obra enteramente neoclásica, pues el edificio se había iniciado desde 1780 y no había podido concluirse ${ }^{2}$ El proyecto que presentó Ortiz de Castro, en 1788, al ingeniero Constansó, como agudamente observó Elizabeth Fuentes Rojas en su comentario a la ponencia citada, perseguía dos fines: uno, "cumplir con las Reales Ordenanzas de presentar los planos de reedificación de la antigua iglesia, y [otro] la de solicitar la evaluación de sus conocimientos en el área de arquitectura, a efecto de obtener el grado de Académico de Mérito". ${ }^{3}$

En su proyecto, Ortiz de Castro propone utilizar parte de la construcción anterior. Con breves modificaciones el proyecto fue aprobado; si bien el edificio, a juicio nuestro, no es del todo afortunado pues el coro, por ejemplo, resulta desproporcionado y aparece ahogado en el primer tramo de la nave.

Es conveniente citar otra obscrvación de Elizabeth Fuentes, en el sentido de que la Academia de San Carlos ejercía, "un sentido de sanción estética... para lograr la unidad artística; por medio de la revisión de los proyectos de construcción de todos sus integrantes, del nombramiento de los tasadores de arquitectura, de la exclusividad de acreditar a los maestros de construcción y de la monopolización de las comisiones públicas". " El triunfo del neoclásico iba en aumento.

\section{Parroquia de Zimapán}

Otra obra dieciochesca muy ilustrativa de la problemática aquí abor dada, es la iglesia mayor del mineral de Zimapán, Hidalgo, iniciada en el segundo tercio del siglo XVIII, la cual sustituyó a una construcción anterior. La riqueza del mineral alentó a los vecinos para iniciar la construcción de uñ

\footnotetext{
2 José Guadalupe Victoria, "Sobre arte ncoclásico en el Estado de Hidalgo". Ponencia presentada en el Primer Encuentro de Historia del Arte en Hidalgo, celebrado en la ciudad de Pachuca, del 22 al 24 de junio de 1988. Las actas de dicho evento se encuentran en prensa.

${ }^{3}$ Elizabeth Fuentes Rojas, "Comentario a la ponencia de José Guadalupe Victoria: Sabre arte neoclásico en el Estado de Hidalgo". En prensa.

${ }^{4}$ Ibidem.
} 
edificio de gran envergadura. El propósito era erigir un edificio barroco, aunque ya para ese tiempo - la década de los ochenta- la Academia de San Carlos de México había sentado sus reales y los zimapanenses hubieron de terminar su iglesia en estilo modemo, es decir neoclásico.

Sin embargo, tal como procuramos mostrar en el trabajo citado anteriormente, se trata de un neoclásico muy sui generis, sobre todo en el interior donde la balaustrada que recorre el perímetro de la nave y el retablo mayor, además del púlpito, ostentan bastantes huellas del arte anterior; es decir del barroco.

San Miguel de las Cuevas de Chalma

Hoy por hoy uno de los santuarios cristológicos más celebres de México, remonta sus orígenes al primer tercio del siglo XVII y no, como señala la piadosa tradición, a recién concluida la conquista de México. Lo cual no quiere decir que no hubiera existido ahí, desde ese entonces, una pequeña ermita visitada por los religiosos agustinos de Oculián o Malinalco, conventos que sí fueron fundados en las primeras décadas de dominio hispánico. ${ }^{5}$ En Chalma se rinde culto a un Cristo hecho en pasta de caña; obra que por mucho tiempo se denominó "el Cristo Negro de Chalma", pero en realidad, tal como lo prueban investigaciones recientes, esa tonalidad la fue adquiriendo debido al humo de los cirios ofrecidos a través del tiempo.

Sin embargo, el gran conjunto de Chalma -iglesia y convento-es obra del primer tercio del siglo XVIII. De ser cierta la información registrada en la Gaceta de México, el 23 de enero de 1730, tuvo lugar la bendición del retablo mayor, cuyo costo rebasó los diez mil pesos; además se informa que la iglesia "tiene setenta varas de largo, y quince de claro, y costó más de setenta mil pesos y se fabricó siendo prelado del expresado observante colegio el R.P. Dr. y Mtro. Fray Juan de Magallanes, quien con incansable aplicación, solicitud y desvelo lo comenzó, continuó y finalizó y dedicó el día 27 de febrero de $1729^{\prime \prime} .{ }^{6} \mathrm{El}$ mismo diario, con fecha 12 de noviembre de 1736, al dar a conocer la muerte del padre Magallanes, señala que él fue "memorable para el santuario y convento de Chalma, cuyo suntuoso templo sacó de cimiento, continuó y acabó en tiempo de nueve años que fue su presidente". ${ }^{7}$ De lo cual inferimos que la obra se inició hacia 1720.

\footnotetext{
${ }^{5}$ Fray Juan de Grijalva, OSA, Crónica de la Orden de N. P. S. Augustin en las Protincias de la Nueva España, México, 1624, Libro Primero.

${ }_{7}^{6}$ Castorena y Ursúa y Sahagún de Arévalo, Gacetas de México, v. I, p. 226.

${ }^{7}$ Ibidem, v. II, p. 375 .
} 
Además del retablo mayor ya mencionado, completaban el conjunto de la iglesia una serie de retablos del mismo estilo y varias capillas anexas; trabajos realizados entre 1730 y 1760 . Todo lo anterior explica la unidad arquitectónica del conjunto, si bien no deja de llamar la atención su exterior neoclásico.

En 1783 los agustinos consiguieron que el rey Carlos III otorgara al santuario el título de Real, y que lo acogiera bajo su patrocinio. ${ }^{8}$ Lo cual hace pensar que, dados los nuevos tiempos que corrían en cuanto a novedades artísticas, se contempló la renovación de algunas partes del santuario, especialmente de la iglesia.

Una de las pinturas conservadas en la sacristía muestra parcialmente el estado que guardaba el edificio a fines del siglo XVIII. Al comparar esa ilustración con el edifico actual se advierte que las adiciones neoclásicas más importantes fueron: la portada, las torres - que antes sólo tenían un cuerpo- y la cúpula. Desafortunadamente no ha sido posible precisar las fechas en que se llevaron a cabo esos trabajos, ni quién los realizó. Lo que salta a la vista es el parentesco de esos elementos neoclásicos, con los de la catedral de México: sobre todo el diseño de las torres con su remate campaniforme.

El interior barroco también fue presa del neoclásico e incluso en los pasados años setenta volvió a redorarse.

\section{San Martín Ocoyoacac}

En un recodo de las estribaciones de la Sierra de las Cruces, sólo que con vista al valle de Matalcingo, se encuentra el pueblo de Ocoyoacac, cuya primera iglesia fue fundada a mediados del siglo XVI por sacerdotes seculares. Sin embargo, debió ser una construcción modesta que fue deteriorándose a lo largo del siglo siguiente. A mediados de la centuria decimoctava los vecinos del pucblo, encabezados por el párroco, iniciaron los trámites para construir una nueva iglesia ${ }^{9} \mathrm{Al}$ parecer, lo único que lograron fue desplantar el edifico y levantar parte de los muros. Sin embargo, dado el alto costo de la obra, no fue posible continuarla quedando en tal

\footnotetext{
${ }^{8}$ Nicolás Téllez Baeza, Historia de la a parición del Señor de Chalma y su convento, México, 1949 y Eduardo Báez Macías, El Arcángel San Miguel, México, UNAM, Instituto de Investigaciones Estéticas, 1979, p. 62

9 Todas las noticias acerca de esta iglesia, aquí consignadas, provienen de documentos conservados en el Archivo General cle la Nación, Ramo Templos y Conventos.
} 
estado de abandono que espantó al cura eclesiástico designado a ese pueblo, a fines de los años setenta, don Manuel de Avila, quien se propuso continuar las diligencias necesarias para proseguir la edificación.

La documentación que consultamos permite afirmar que al inicio de los años ochenta, gobernando el virrey don Matías de Gálvez, se autorizó que del ramo de los tributos del pueblo se entregaran mil pesos para iniciar los trabajos. Cantidad puesta en manos de don Juan García de Figueroa, vecino del pueblo y tesorero de la obra, quien utilizó el dinero en beneficio propio. Por esa razón el cura de Ocoyoacac inició un pleito en contra de Juan de Figueroa recurriendo a las autoridades capitalinas. No es el caso señalar los detalles de tan bochornoso incidente que concluyó con el embargo y venta de los bienes de Figueroa; es suficiente indicar que el párroco logró hacer ver el ruinoso estado de la iglesia, para lo cual no escatimó argumentos que pudieran tocar lo más profundo de la conciencia de las autoridades. Decía: "no es fácil explicar a V. E. el estado deplorable de mi iglesia. En alguna ocasión he tenido el grave sentimiento de ver volar en fuerza del aire desde al ara del Divinísimo. Este está expuesto continuamente a los insultos a que no se expondría en la casa del indio más infeliz. No hay animal cuya inmundicia no llegue a lo más sagrado del altar; y sucede no pocas veces quedarse sin luz el sacramento, no obstante el farol de cristal que cubre el vaso de la lámpara. En este tiempo la mayor parte del pueblo omite su asistencia al santo sacrificio de la misa en los días festivos por no exponerse a una enfermedad que ciertamente causaría lo copioso y frecuente de las aguas. $Y$ todo, ¿por qué? Por la inacción del tesorero que en el espacio de ocho años no ha puesto una sola piedra sobre las paredes de la iglesia. ${ }^{\text {"10 }}$

El pleito continuó y una vez terminado resultó indispensable hacer un nuevo avalúo de la obra existente y cálculo de la nueva. El párroco, recogiendo el sentir de los vecinos quienes treinta años antes habían calculado invertir alrededor de quince mil pesos, manifestó que la obra alcanzaría la suma de 16 mil.

Ahora bien, aunque hay un vacío en la documentación, podemos suponer que los trámites continuaron y que los mil pesos cobrados a don Juan de Figueroa fueron insuficientes para iniciar las obras. Las autoridades de la capital ordenaron - ya en los años noventa- inspeccionar la obra recomendando que fuera cubierta con artezón, a fin de economizar. Esta recomendación fue tomada en cuenta por don Juan Antonio Flores

${ }^{10}$ Ibidem 
- subdelegado de Santiago Tianquiztenco- quien en 1793 nombró un perito para que fuera a Ocoyoacac. Aunque lo que faltaba era dinero, Flores designó para tal empeño nada menos que a don Antonio [González] Velásquez, director del ramo de arquitectura de la Real Academia de San Carlos. Hecho que también podría explicarse dada la cercanía con la capital ya que en la jurisdicción no había quién pudiese llevar a cabo dicha comisión.

Al maestro Velásquez, quizás no debió interesarle mucho la obra pues envió a un subalterno. Con base en los informes que le rindió, el académico elaboró, indican los documentos, diseños de la obra y estableció el costo de la misma. No hemos localizado tales diseños - que deben parar tal vez en el archivo de la Academia - en cambio el informe rendido por Velásquez, el 6 de octubre de 1793, señala que la obra tendría un costo de 22610 pesos. Vale destacar de ese informe el hecho de que el maestro se opusiera a que la iglesia fuera cubierta con artezón, dado que en la región sólo había oyameles y la madera usual en ese tipo de trabajos era el cedro $y$, llevarlo de otros lugares, sería tan costoso como la fabricación de una bóveda. Además de que se corría el riesgo de que la iglesia pudiera incendiarse como había ocurrido en las iglesias de Jilotepec, Tenango del Valle y Chapa de Mota, lugares que actualmente caen en la jurisdicción del estado de México.

Concluye Velásquez diciendo: "mi sentir es que son necesarias

Para todo el Cañón de Bóveda y Cruceros .................... 9450

Por la media Naranja y sus Claraboyas.......................... $\quad 4300$

Por los Arcos del Cuerpo de Yglesia y Ventana .......... $\quad 2300$

Por reformar las Paredes y estribos............................... $\quad 1100$

Por el coro y fachada principal ........................................ 2200

Madera de Andamios, lazos y reatas.............................. 1900

El envigado de la Yglesia.................................................. . $\quad 760$

QUE TODO IMPORTA... $\quad 22610^{\prime \prime \prime 11}$

La suma anterior pareció excesiva, pero aún así, se decidió iniciar los trabajos. Para lo cual, además de la ayuda de las autoridades de la capital, a través de la Real Hacienda, participarían los vecinos del lugar, quienes prometían lo siguiente:

${ }^{11}$ Ibidem. 
DOI: http://dx.doi.org/10.22201/iie.18703062e.1990.61.1562

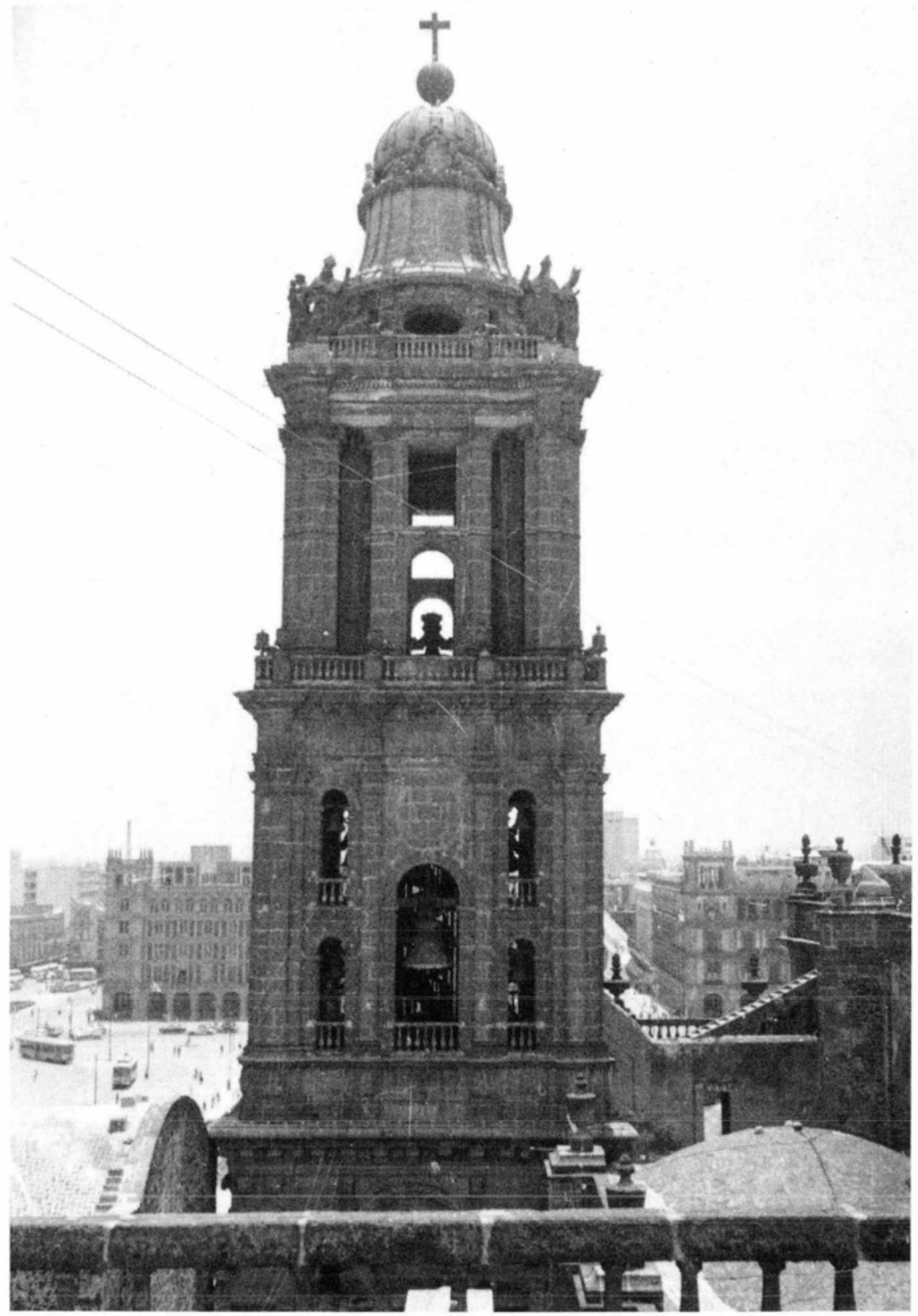

1. Catedral de México. José Damián Ortiz de Castro. Torre derecha. 


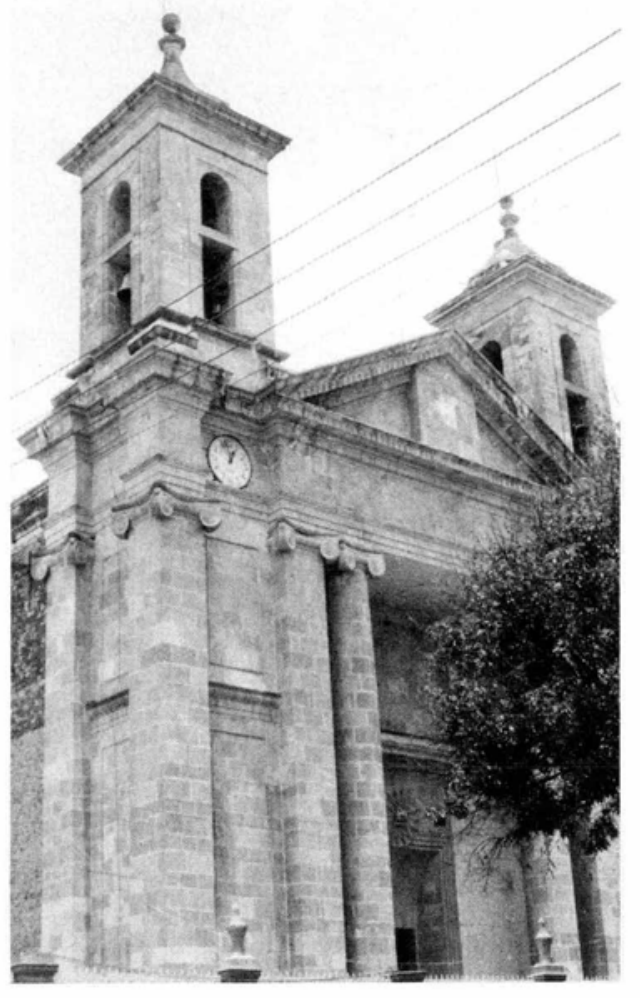

2. Parroquia de Tulancingo, Hgo. (hoy Catedral). José Damián Ortiz de Castro.

Fachada principal.

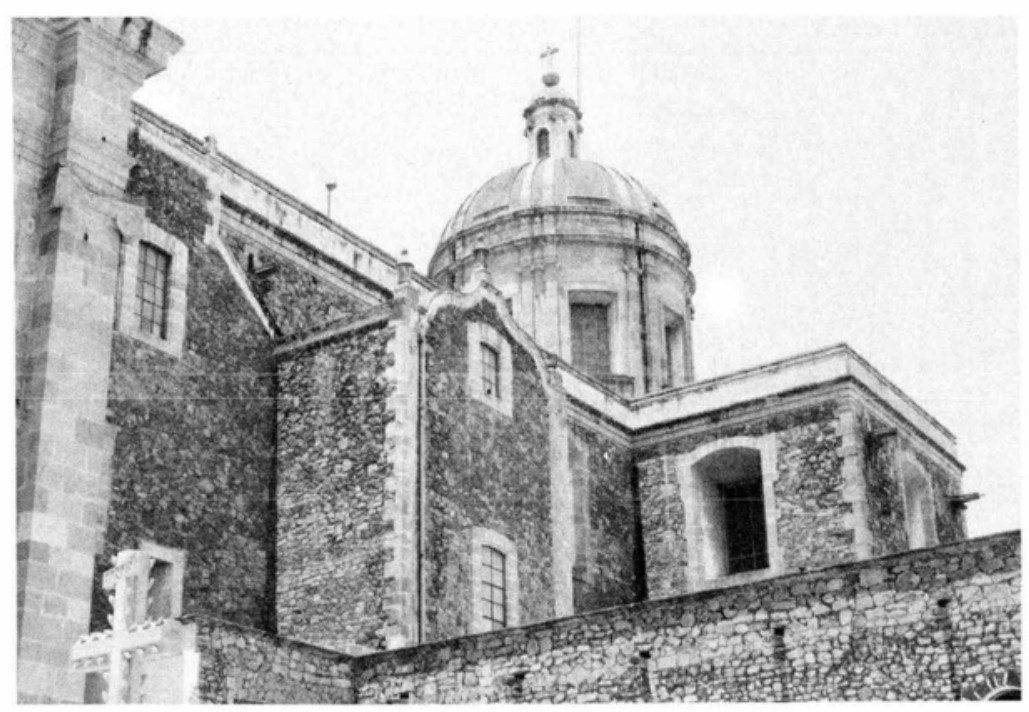

3. Parroquia de Tulancingo, Hgo. (hoy Catedral). José Damián Ortiz de Castro.

Cúpula. 
DOI: http://dx.doi.org/10.22201/iie.18703062e.1990.61.1562

4. Parroquia de Tulancingo, Hgo. (hoy Catedral).

José Damián Ortiz de Castro.

Interior.
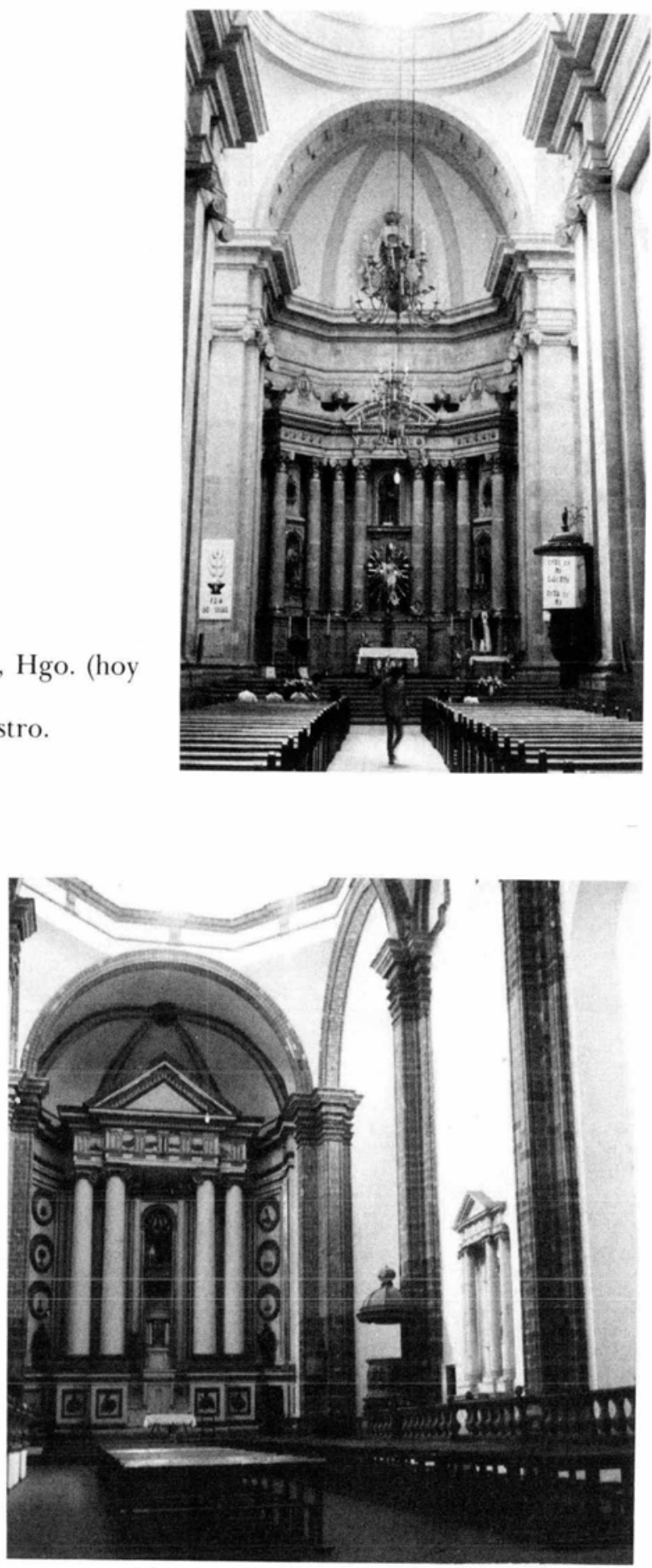

5. Parroquia de Zimapán, Hgo. Interior. 
DOI: http://dx.doi.org/10.22201/iie.18703062e.1990.61.1562

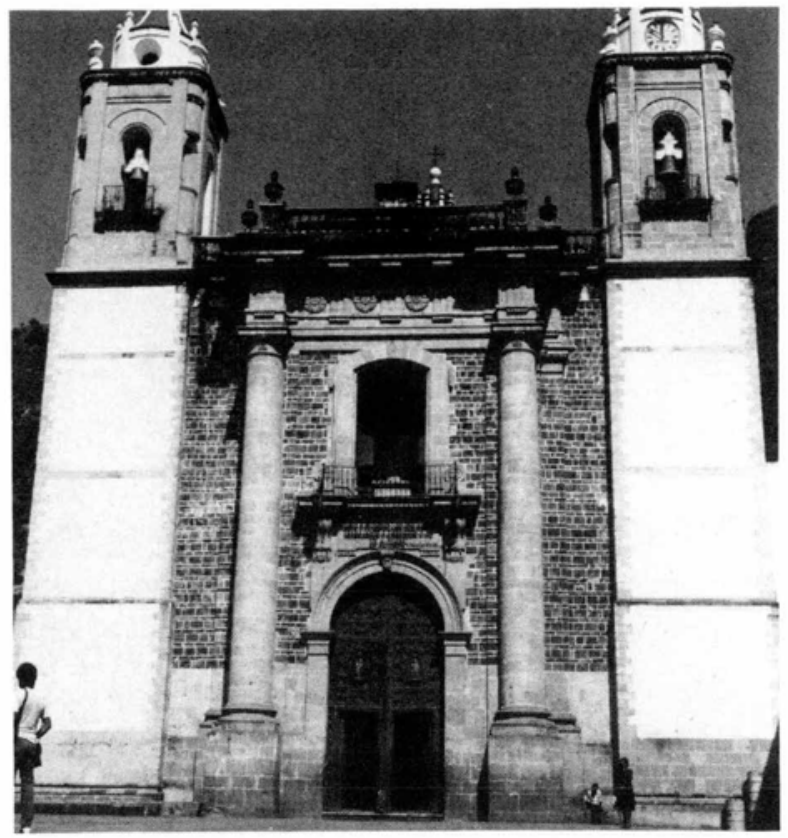

6. Fachada principal del santuario de Chalma, Méx.

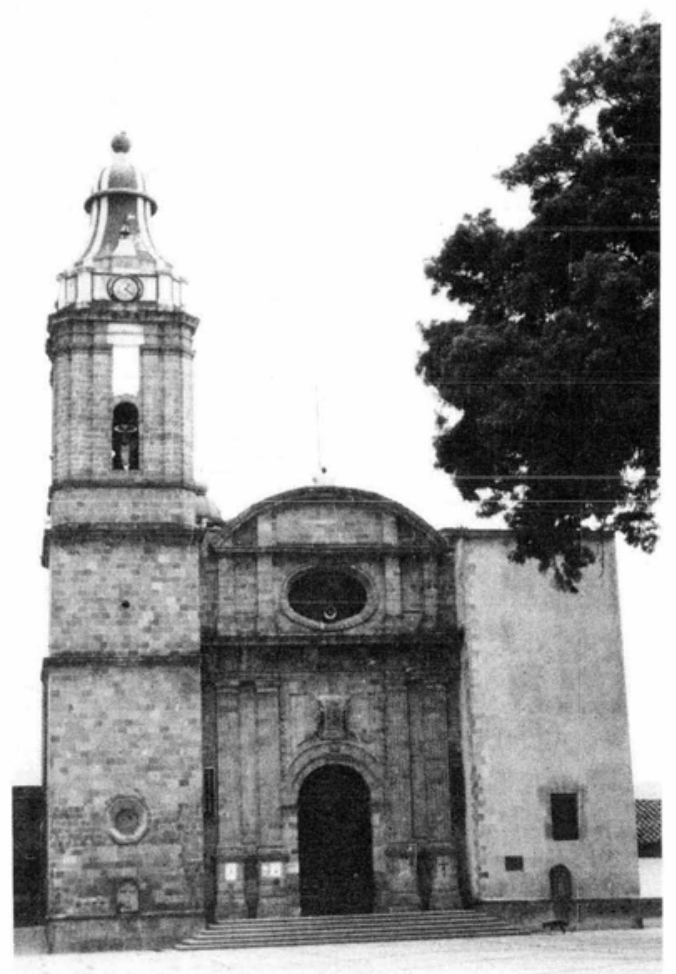

7. Parroquia de San Martín Ocoyoacac, Méx. Antonio Velázquez.

Fachada principal. 
DOI: http://dx.doi.org/10.22201/iie.18703062e.1990.61.1562

8. Parroquia de San Martín Ocoyoacac, Méx. Antonio Velázquez.

Fachada principal (pormenor).
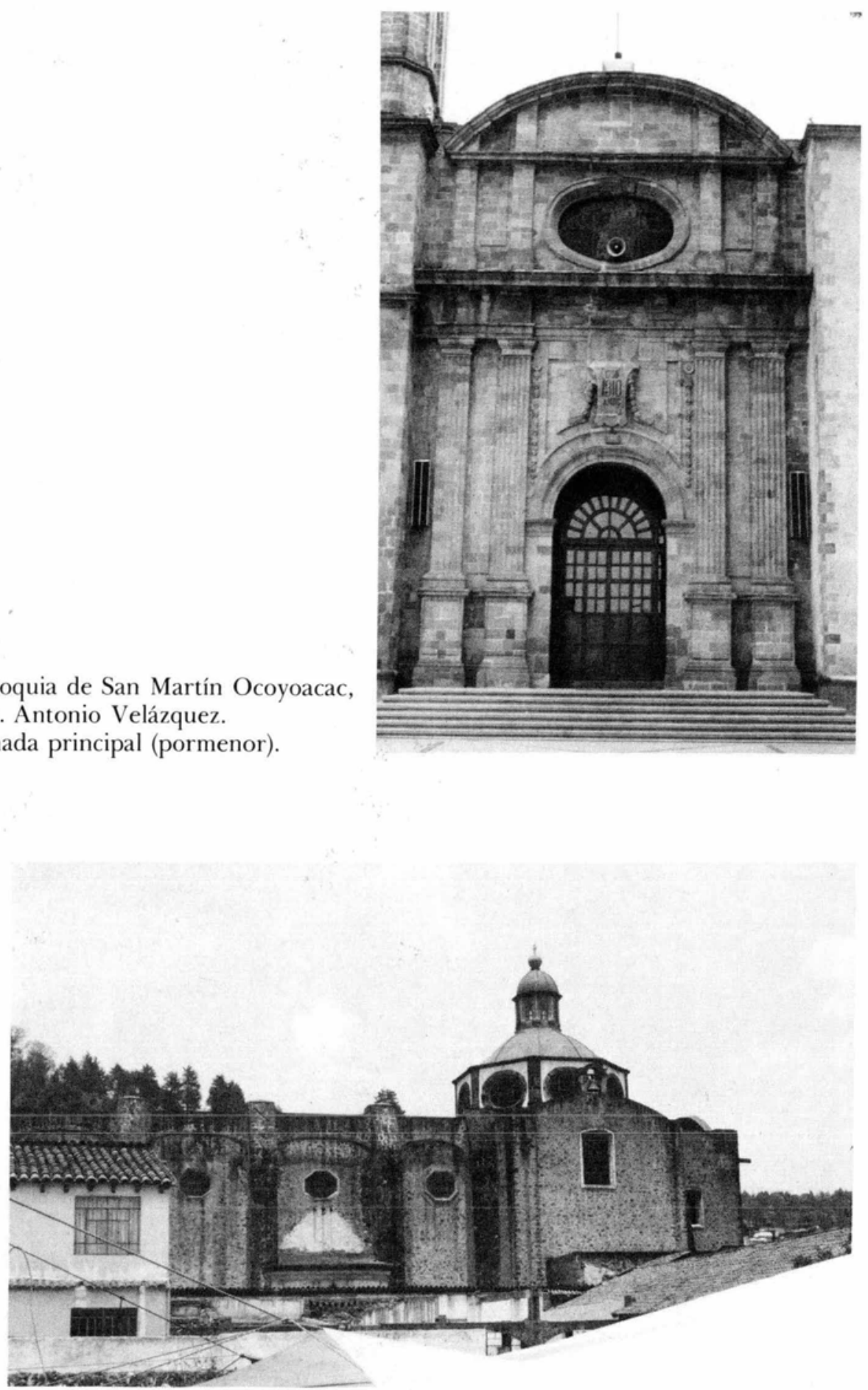

9. Parroquia de San Martín Ocoyoacac, Méx. Antonio Velázquez.

Fachada sur. 
DOI: http://dx.doi.org/10.22201/iie.18703062e.1990.61.1562

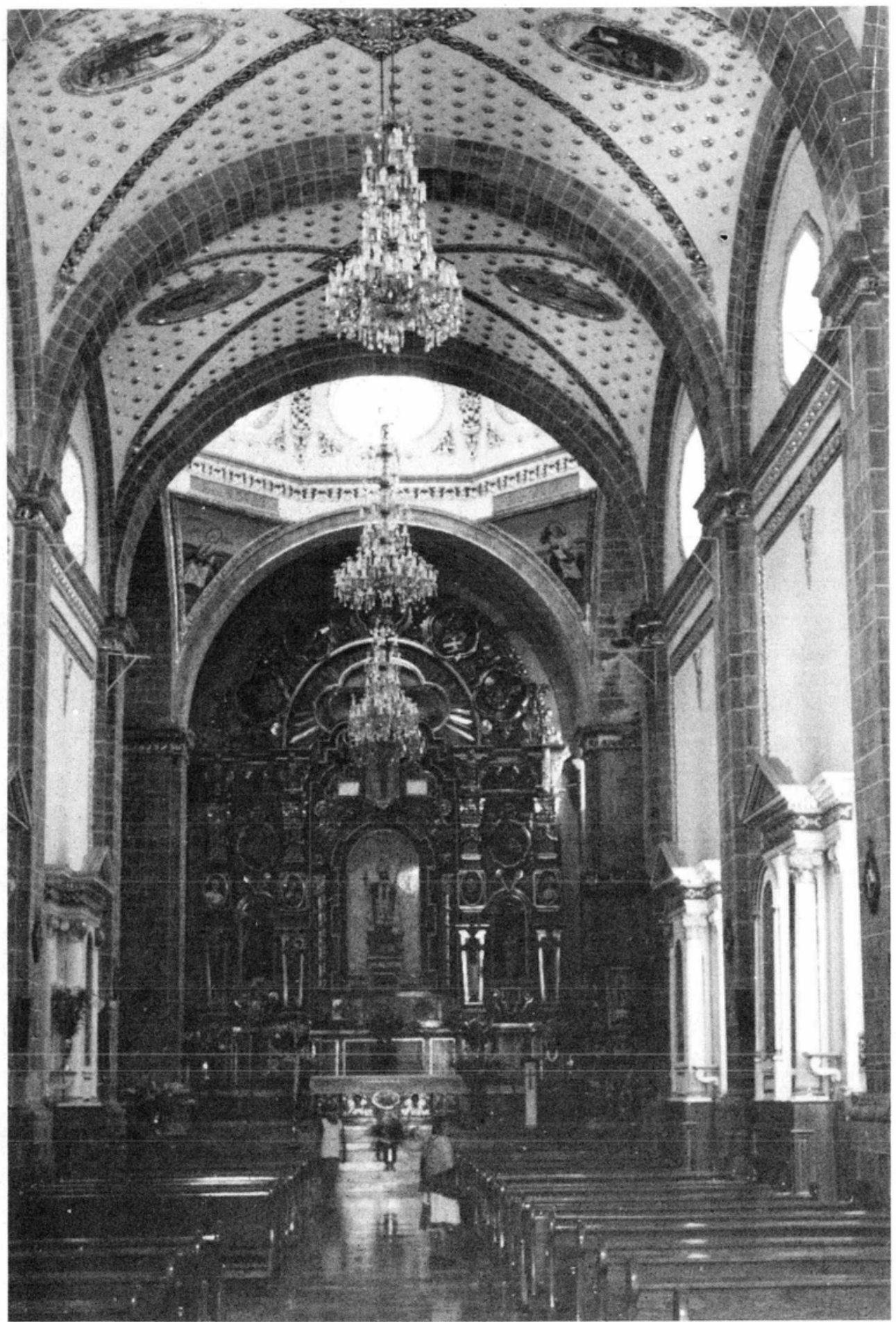

10. Parroquia de San Martín Ocoyoacac, Méx. Antonio Velázquez. Interior. 
$1^{\circ}$. Que los arrieros o dueños de mulas las suplen gustosos para la conducción de cal, cantería, tezontle, y otros materiales de esta clase $2^{\circ}$ Que los indios de los cuatro barrios: [San Pedro] Cholula, San Miguel, Santa María [Capanoaya] y Santiago trabajaran por un medio real menos de jornal en cada día: $3^{\circ}$. Que en fuerza de las exhortaciones del Cura a los Yndios de dichos barrios ofrece cada familia un real semanario [que] al fin del año suman como quinientos pesos. $4^{\circ}$. Que siendo del superior agrado de V.E se dignará mandar a los pueblos de Atlapulco y Acazulco, ayuden con las maderas necesarias para la cimbra y envigado de la iglesia, ${ }^{12}$

Velásquez se hizo cargo de la obra y el resultado fue la iglesia que puede apreciarse en las ilustraciones, cuya nota predominante son sus grandes dimensiones y masividad. Los elementos neoclásicos se advierten sobre todo en la fachada, en cuyas torres se nota la impronta de la catedral metropolitana, sobre todo en la proporción de sus cuerpos y el remate campaniforme. El interior es significativo por su amplitud, que lo aproxima a otras obras de Velásquez como la iglesia de San Pablo el Nuevo en la Ciudad de México.

\section{Conclusión}

Habiendo llegado a este punto vale la pena hacer varias consideraciones En primer lugar, tal como se señaló al principio de este trabajo, el intenso ritmo constructivo que tuvo lugar en la Nueva España entre 1730 y 1780. No obstante, en muchos casos - como los aquí estudiados- los recursos económicos no eran suficientes para concluir esos edificios, concebidos dentro de los lineamientos del barroco, razón por la cual los interesados - religiosos y autoridades civiles menores-, hubieron de iniciar trámites fastidiosos con el fin de lograr se les otorgara dinero para concluir los trabajos. Dado que dichos trámites debían hacerse entre las autoridades locales y el gobierno central, se ponía de manifiesto la lentitud burocrática; lo cual redundaba en el retraso de las obras. Dicha tardanza, unida al regateo de las cantidades a otorgar fue la causa de que los edificios no fueran enteramente nuevos, sino que se aprovecharan estructuras existentes; aspectos que ilustran perfectamente iglesias de Zimapán, Tulancingo y Ocoyoacac.

De manera que los arquitectos escogidos hubieron de condicionar o adecuar sus proyectos, lo cual, ciertamente, representó una limitación; así lo

${ }^{12}$ Ibidem. 
prueba el resultado final, específicamente en los casos de Tulancingo y Ocoyoacac. En el primero de ellos la nave resulta demasiado larga; por lo que el coro se pierde. La altura también resulta excesiva y las torres apenas si establecen cierta armonía con la cúpula. Cabe añadir que la manera de estructurar las torres recuerda el máximo templo catedralicio de México.

En la parroquia de Ocoyoacac, Velásquez se salió con la suya en cuanto a lograr que se aceptara la construcción de una bóveda, en lugar del artezón; solución arquitectónica por la que todos se inclinaban. La iglesia es de grandes proporciones y el coro también resulta pequeño en relación a la nave. Sin embargo, la impronta neoclásica es más evidente en la portada y en la torre; elementos arquitectónicos donde se advierte también, la influencia de la catedral de México.

Ahora bien, la información documental acerca de este monumento da pauta para referirse a otros problemas que muchos historiadores del arte novohispano han cludido, o sea el que se refiere a las condiciones socioeconómicas en que surge la obra. El caso de Ocoyoacac muestra, entre otras cosas, la pobreza de esa región tan cercana a la capital, cuya fuente principal de riqueza era la agricultura, pero que deseaba contar con un gran edificio. Ya hemos visto cuál pudo ser su contribución; las autoridades locales recurren al centro - a Real Hacienda especialmente- para solicitar ayuda. Y aunque no se mencionó anteriormente, también se obligó a los españoles residentes en el lugar para que contribuyeran. En el caso de los indios su contribución no era en dinero, sino más bien en especie y con fuerza de trabajo.

Lo anterior hace pensar en el primer siglo de vida novohispana; sin embargo, se vivía en plena Ilustración, cuando el auge de los gremios tocaba a su fin y se suponía un enfrentamiento -o al menos un cambioen la manera de trabajar. Lo que interesa en el caso de Ocoyoacac es que la supuesta modernidad no era tanta, por más que se haya escogido a Antonio Velásquez para dirigir la obra. Arquitecto que a los ojos de Toussaint, no es de los mejores. Juicio injusto del maestro, en tanto no conozcamos un número mayor de obras construidas por el director de arquitectura en la naciente Academia.

Ahora bien, un úliimo punto a considerar se refiere al aspecto formal de los edificios: los ejemplos citados son, por su planta y alzado barrocos, aunque por su acabado - según asentamos- se les considere neoclásicos. No obstante, el manejo del lenguaje clásico, resulta sui generis, confiriendo a los edificios cierto carácter regional (?), que en vano buscaríamos en las obras capitalinas. ¿Qué fue lo que les imprimió ese carácter local? Sin poder dar una respuesta, vale la pena citar otros ejemplos aún no estudia- 
dos en los que también advertimos cierta diferenciación. Las iglesias de Santa Clara de Lerma, Gualupita, Capulhuac, Tenango del Valle y la parroquia de Tenancingo. La lista podría continuar, pero nos interesa rctomar el parecer de Elisa Vargas I ugo -expresado hace ya veinte años-en el sentido de que en la Nueva España, pese al breve tiempo que dura el arte neoclásico, hay suficientes obras que permiten distinguir dos centros: México y Celaya. Las obras aquí presentadas - y otras más aún no registradas - permiten considerar que hay un tercer foco de neoclasicismo. Sería interesante determinar si ese tercer foco es autónomo o depende ciento por ciento de la capital.

Falta estudiar la arquitectura que va de la fundación de la Academia a la consumación de la Independencia, para conocer un mayor número de obras que den validez a los planteamientos anteriores. En el caso de llegar a comprobarse algunos de ellos, tendríamos que convenir que, como en el del barroco, en el neoclásico también se dio una regionalización.

Por último indicaremos que si hay algo novedoso en este trabajo, es el hecho de dar a conocer una obra - la parroquia de San Martín Ocoyoacac, México- que hasta el presente había pasado desapercibida por los historiadores del arte novohispano. Obra del arquitecto Velásquez, cuyo trabajo espera ser valorado y estudiado. Al hacerlo se entenderá mejor una etapa de arte mexicano que, con leves imutaciones, terminó de formar y conformar la imagen de muchas de nuestras ciudades, hoy tan degradadas, vilipendiadas y bocabajeadas, nada menos que por arquitectos que a veces ni siquiera saben lo que fue la Academia.

\section{DOCUMFNTO No. 1}

El Director de Arquitectura de la Real Academia de San Carlos de Nueva España y Académico de mérito de la Real de San Fernando de Madrid

De Comisión de el Sub-Delegado de Tenango de el Valle Don Juan Antonio Flores he formado los adjuntos diseños para la conclusión de la Yglesia Parroquial de San Martín Ocoyoacac y el presupuesto de su costo; a cuyo efecto siendome imposible pasar personalmente a dicho Pueblo embie Sujeto que merece mi confianza quien formó exactos diseños de la Fábrica existente, y me instruyó suficientemente en las calidades, y proporciones de los materiales de que podría formarse.

Y aunque dicho Sub-Delegado me previno ser Orden Superior, que la Yglesia se cubriere de Artesón para descargo de mi conciencia y por que en lo sucesivo no se me impute qualquier defecto, tuve a bien hacerle presentes los 
inconvenientes que ofrece este género de cubierta consultando a la subsistencia de la obra, y por consiguiente a los intereses del Soberano, que desde luego no deben invertirse en obras inútiles

La madera que presentan aquellos Montes inmediatos es la Ordinaria que se llama Oyamel, y en el caso de que de esta se cubriera la Yglesia, era indispensable su reparto por lo menos en cada quinquenio, y si para ocurrir a este daño se sobrepusiere el Artesón otra cubierta de tajamamil, lo alto de ésta y los continuos Vracanes de aquellos Países hacen temer su destrucción como se ha experimentado otra ocasión en la Carsel de aquel Pueblo teniendo diez varas menos de altitud. La única madera propia para este género de cubierta es el Cedro, y este está en tal distancia que sin duda ofrece tantos o más gastos de los que regulo en mi cálculo necesarios para la decente conclusión de la Yglesia.

A esto se agrega la corriente observación de que las Yglesias del Reyno por lo común se incendian como se visto en la antigua de Xilotepec, con la de Tenango del Valle, Chapa de Mota, la de San Augustin de esta Ciudad, y otras muchas y ciertamente a este riesgo no mui remoto quedaría expuesta la de Ocoyoacac cubierta de Artezón

En qonsecuencia de estas razones, y de que necesita todas las Bóvedas y media Naranja para lo cual es necesario reformar los gruesos machones exteriores o estribos, en parte cerrar las Bóvedas en arista saliente para su mayor permanencia, y la media Naranja formando en ella misma las claraboyas, que el diseño demuestra, omitiendo el Cuerpo de luces tanto para economizar el costo, como para mayor seguridad en menor elevación, mi sentir es que son necesarios.

Para todo el Cañón de Bóveda y Cruceros .................... 9450

Por la media Naranja y sus Claraboyas.............................. $\quad 4300$

Por los Arcos del Cuerpo de Yglesia y Ventana ............. 2300

Por reformar las Paredes y estribos ..................................... 1100

Por el Coro y fachada principal .................................... $\quad 2200$

Madera de Andamios, lazos y Reatas.......................... 1900

el envigado de la Yglesia.........................................

QUE TODO IMPORTA $\quad 22610$

Es quanto puedo decir en el particular jurando todo lo necesario. México y Octubre seis mil setecientos noventa $y$ tres años 


\title{
DOCUMENTO No. 2
}

\author{
México, Noviembre 14 de 1793
}

Al Sr. Fiscal de la Real Hacienda donde estan mandados parar los antecedentes.

En cumplimiento de la última orden del $\mathrm{Sr}$. Intendente comunicada a mi interino que fue de esta jurisdicción Subdelegado de Lerma Dn . José Martínez de Castro, su fecha cinco de abril último le previne nombrar a un perito que pasase a reconocer la iglesia de San Martín Ocuyacac levantase planos y avaluase los costos que puede importar su conclusión: Para el efecto nombré a Don Antonio Velásquez Director de Arquitectura en la Real Academia de San Carlos de N. E. y Académico de méritos en la de San Fernando de Madrid, quien instruido de las calidades y proporción de los materiales (ilegible) paises formó los diseños y cálculo que presentó a $\mathrm{V}$. E

La obra no hay duda que es recomendable por su objeto y la suma indecencia con que a pesar del celo y natural aseo del cura, está el sacramento exigiendo toda la atención de V. E. Pues en distintos días festivos que he asistido en aquella iglesia al santo sacrificio de la misa he observado la grande incomodidad con que los feligreses asisten viendose muchos de ellos obligados, a privarse de este precisoso fruto por no estar expuestos al sol, aire, o agua, que mortifica a los otros por no tener cl cuerpo de la iglesia una tabla que sirva de cubierta: el cura me significa que así lo representa a $V$. E y que en distintas ocasiones se le ha volado la forma de los corporales

Este es un mal gravísimo a que ciertamente no se ocurrirá, si V. E no aplica al menos una de las tres partes que el perito calcula necesarias para la obra

El vecindario ha levantado las paredes hasta el arranque de las bóvedas en que se han invertido más de veinte mil pesos sin que hasta (a)hora hay contribuido el soberano en cantidad alguna, pues aunque en poder del Administrador de Tabacos de esta jurisdicción para un mil pesos destinados para aquella iglesia, no se ha tomado un medio real de ellos respecto a considerar que nada adelanta la obra con tan corta cantidad.

Los advitrios que ofrece la vecindad son estos: lo Que los arrieros o dueños de mulas las suplen gustosos para la conducción de cal, cantería, tezontle, y otros materiales de esta clase. 20. Que los indios de los cuatro barrios: Cholula, San Miguel, Santa María y Santiago trabajaran por un medio real menos de jornal en cada día: 3o. Que en fuerza de las exhortaciones del Cura a los Yndios de dichos barrios ofrece cada familia un medio real semanario que al fin del año suman como quinientos pesos 4o. Que siendo del superior agrado de $V$. E. se dignara mandar a los pueblos de Atlapulco y Acazulco, ayuden con las maderas necesarias para la cimbra y envigado de la iglesia

Es cuanto puedo representar a la grandeza de $V$. E en virtud de las superiores órdenes que para en este Archivo, para que determine lo que sea de su agrado que sera como siempre lo mejor: Teanquistengo Doce de octubre de mil setecientos noventa y tres

Exmo. Sr.

Juan Antonio Flores 


\section{DOCUMENTO No. 3}

Don Antonio Velazquez Director de Arquitectura de la Real Academia de San Carlos, ante V. E dice que habiéndose hecho cargo de la fábrica material de la Yglesia Parroquial de S Martín de Ocuyoac para la que S. M. Dios guarde (?) (sic), dió la cantidad de trece mil pesos, pasó a hacer reconocimiento de las paredes y demás que se había empezado a fabricar y hecha una exacta inspección de todo segun mi reconocimiento advertí ser capaces de poder sobstener bóvedas, y puesto por obra apenas se había verificado la conclusión de dos de ellas, quando inmediatamente se reconoció haber padecido ésta quebrantos, y tanto que según relación que me hizo el sobrestante que le tengo de pie allí amenazaban ruina, lo que inmediatamente que supe pase a dicho curato tanto para hacerme cargo de la rela (ción) que se me había hecho como también para ver los remedios que se podian tomar, para esto hice reconocimiento de los cimientos y advirtiendo estar estos fabricados de piedra y lodo incapaz no solo de poder sobstener bóvedas que ya se hallaban fabricadas sino juntamente poder poner las que faltaban, ocurri al arbitrio de levantar, reforzar y crecer unos estribos que dicha Yglesia tenía y al mismo tiempo en el enra(z) sic de la bóveda el amarrarlas con unas planchas reforzando en la parte posible los cimientos; en cuyas operaciones se ha imbertido la cantidad de tres mil pesos como consta de las memorias de los que al principio de la obra no se hizo consideración ninguna por no haver segun lo exterior manifestaba fundamento el mas leve para ello, y los mismos que segun tengo reconocido se necesitan para la perfecta conclusion de la fábrica y sin los que no podrá verificarse sino que antes al contrario los 13 mil pesos que $S$. M. tiene dados, como también el trabajo personal que en el espacio de dos años han tenido los Yndios y Feligreses de aquella Parroquia serán infructuosos pues con el transcurso del tiempo (?) y copia de aguas que anualmente se experimenta en dicho pueblo puede arruinarse todo lo fabricado. Lo que por cierto a pedimento del cura de la expresada parroquia hago aparente a $\mathrm{V} . \mathrm{E}$.

Exmo Señor

Antonio Velásquez 